\title{
Treatment of Materials Contaminated with Polychlorinated Biphenyls (PCBs): Comparison of Traditional Method and Supercritical Fluid Extraction
}

\author{
Dannielle Jannaine Silva ${ }^{1}$, Felipe V. Pietri² ${ }^{2}$ José Ermirio F. Moraes ${ }^{2}$, Reinaldo Camino Bazito ${ }^{3}$, \\ Camila Gambini Pereira ${ }^{1^{*}}$ \\ ${ }^{1}$ Department of Chemical Engineering, Federal University of Rio Grande do Norte, Natal, Brazil \\ ${ }^{2}$ Department of Chemical Engineering, Federal University of São Paulo, São Paulo, Brazil \\ ${ }^{3}$ Department of Chemistry, University of São Paulo, São Paulo, Brazil \\ Email: "camila@eq.ufrn.br
}

Received October 3, 2012; revised November 5, 2012; accepted November 13, 2012

\begin{abstract}
The objective of this study was to develop an experimental methodology for the extraction of polychlorinated biphenyls (PCBs) from contaminated soil and wood material using the Soxhlet extraction method and supercritical fluid technology. The sample PCB contents were quantified using Gas Chromatography-Mass Spectrometry (GC/MS). Conventional extractions of PCBs from soil samples showed higher extraction yields for samples with the highest initial PCB levels and longest extraction times. Specific PCBs yielded 74.0\% - 78.3\% removal using ethanol as the solvent. 91.0\% 94.3\% removal of the total PCB content was achieved using hexane as the solvent. Supercritical fluid extraction of soil samples resulted in 50.0\% - 70.5\% removal for specific PCBs and 57.3\% removal of the total PCB content. For wood, the use of Soxhlet extraction resulted in $87.0 \%-94.0 \%$ removal for specific PCBs and $95.0 \%-96.3 \%$ removal of the total PCB content. Supercritical fluid extraction of wood samples resulted in $91.1 \%-95.0 \%$ removal of specific PCBs and $95.1 \%$ of the total PCB content.
\end{abstract}

Keywords: Polychlorinated Biphenyls; Extraction; Soil; Wood

\section{Introduction}

Polychlorinated biphenyls (PCBs) are highly toxic, chlorinated organic substances that are considered persistent organic pollutants. They do not easily degrade due to their high thermal and chemical stability. Therefore, when these substances are released into the environment, they accumulate in ecosystems and are incorporated into the food chain, resulting in biomagnication [1-3]. PCBs are composed of two, six-carbon aromatic rings containing multiple chlorine atoms (Figure 1) with 209 possible congeners. However, only 130 PCB congeners have been detected in commercial products $[3,4]$.

The toxicity of individual PCBs is determined by their structure and number of chlorine atoms. PCBs with more chlorine atoms are more toxic [5]. Accumulation of PCBs in the body can cause a number of health problems, including cancer, immune suppression, reproductive damage, birth defects, and fetal death $[5,6]$. In the 1970s, PCBs were produced for a number of uses including thermal exchange fluids in heat exchangers, lubricants, iso-

${ }^{*}$ Corresponding author. lating fluids in electrical equipment, resins and pesticides. Due to their high toxicity, in 1970s, the manufacture and commercial use of PCBs was banned $[7,8]$. Although the production of PCBs has been banned, they are still found in the environment. According to Brazilian regulations, materials contaminated with greater than 50 ppm PCBs must be stored under specific conditions or destroyed, usually by incineration in plasma furnaces with dual steps [9]. However, transportation of PCB contaminated materials requires specific conditions that are expensive and incineration itself is a costly process [1012]. Extraction of PCBs from contaminated samples using new methodologies $[5,13]$ can be used to significantly decrease the amount of contaminated material requiring storage or incineration [5,14]. Soxhlet has been used as standard technique during more than one century. This technique is a very simple, cheap and provides good reproducibility. However, Soxhlet is not a selective process. Microwave-assisted extraction, accelerated solvent extraction and Supercritical Fluid Extraction (SFE) are techniques that use smaller amounts of organic solvents than conventional extraction methods $[15,16]$. Extraction of PCBs from seaweed samples and sediments 
using supercritical fluid extraction has been demonstrated previously [17-19]. Nevertheless, up to now the researches did not compare the extraction of $\mathrm{PCBs}$ from wood and soil contaminated using these different methodologies. Besides, most work with contaminated materials is related to soil and sediments, and not with wood. The objective of this study was to develop an experimental methodology for the removal of PCBs from contaminated materials, soil and wood, using conventional Soxhlet extraction methods and Supercritical Fluid Extraction (SFE).

\section{Experimental}

\subsection{Simulated Contamination of Wood and Soil Materials}

Simulated contamination of wood and soil samples for use in this study was carried out as below. Samples were macerated and then separated through sieves $(<2 \mathrm{~mm}, 10$ mesh). $40 \times 10^{-3} \mathrm{~kg}$ of sample was suspended in $100 \mathrm{~mL}$ of hexane with $2.4 \times 10^{-3} \mathrm{~kg}$ of a mixture of PCBs (As$\left.\mathrm{karel}^{\circledR}\right)$. The samples were then homogenized in a shaker (Kline Spencer Scientific, Model 109-1TC) for $3 \mathrm{~h}$. The material was then left to rest for four days at room temperature and pressure to allow evaporation of all solvent. The simulated contamination resulted in materials with $60.000 \mathrm{mg}$ PCBs/kg material.

The main properties of the soil, characterized in previous work [20], are presented in Table 1. The wood used was a mixture of Pine (Araucaria angustifolia), Jatoba (Hymenaea sp.) and Timborana (Clathrotropis macrocarpa). The material was collected from a carpentry in Cubatão-SP, without treatment or characterization.

\subsection{Soxhlet Extraction}

Samples of contaminated materials $\left(3 \times 10^{-3} \mathrm{~kg}\right)$ were extracted with $100 \mathrm{~mL}$ of solvent using a conventional Soxhlet apparatus (Gerhardt, Model Soxtherm Multistat/SX PC), with reflux of $10-420$ minutes at $180^{\circ} \mathrm{C}$ and atmospheric pressure. The solvents used were hexane (Synth, P.A, Lot 109169) and ethanol (CAAL, 99.5\%, P.A., Lot 11460). After the required extraction time, the extracts were made up to $100 \mathrm{~mL}$ with solvent. All extractions were carried out in triplicate.

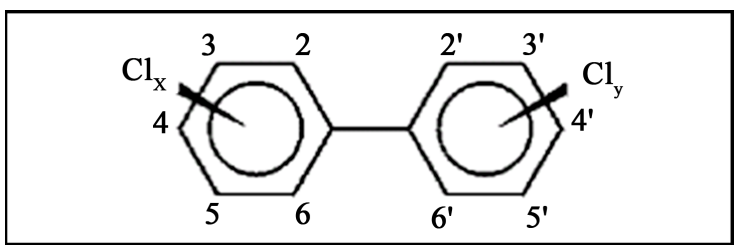

Figure 1. PCB Chemical Structure. $x$ and $y$ indicate the number of chlorides $(x+y \leq 10)$.
Table 1. Soil properties [17].

\begin{tabular}{ll}
\hline \multicolumn{1}{c}{ Properties } & \multicolumn{1}{c}{ Value } \\
\hline Composition & Clay (39.93\%), Silt $(9.01 \%)$, \\
& Sand $(49.22 \%)$ \\
Humidity & $1.63 \%$ \\
$\mathrm{pH}$ & 5.0 \\
Organic Materials & $8.32 \%$ \\
Specific Superficial Area & $24.52 \mathrm{~m}^{2} / \mathrm{g}$ \\
\hline
\end{tabular}

\subsubsection{Preliminary Study}

Before the systematic extraction experiments, a preliminary study of Soxhlet extraction was carried out to determine optimum conditions for the soil extractions. The objective of the preliminary study was to determine the optimum extraction time (from 10 to 420 minutes) and solvent (hexane and ethanol). Four experimental extractions (Tests 1 - 4) were carried out as follows. Test 1 was carried out using soil contaminated with $6.000 \mathrm{mg}$ of Askarel $^{\circledR} / \mathrm{kg}$ soil with hexane as the solvent. Test 2 was carried out using soil contaminated with $60.000 \mathrm{mg}$ of Askarel ${ }^{\circledR} / \mathrm{kg}$ soil with hexane as the solvent. Test 3 and Test 4 were carried out under the same condition as Tests 1 and 2 respectively with ethanol as the solvent. All experiments were carried out using the Soxhlet method at $180^{\circ} \mathrm{C}$.

\subsubsection{Experimental Design}

After the preliminary tests, an experimental design experiment was carried out using two plans ( $\mathrm{H}$ and $\mathrm{E}$ ) and a full factorial design (22) with three replicates at the design centre point. The two independent factors were investigated at three different levels $(-1,0,+1)$ at initial PCB concentrations of 6.000 and $60.000 \mathrm{mg}$ of Aska$\mathrm{rel}^{\circledR} / \mathrm{kg}$ of soil and at extraction time of 20 and $300 \mathrm{~min}-$ utes ( -1 and +1 , respectively). The range and centre point values of the independent variables were chosen based on the results of preliminary study [21]. The difference between plans $\mathrm{H}$ and $\mathrm{E}$ was the solvent used: hexane was the solvent for plan $\mathrm{H}$ and ethanol was the solvent for plan E.

\subsection{Supercritical Fluid Extraction}

Around $5 \times 10^{-3} \mathrm{~kg}$ of materials was used for each supercritical fluid extraction. The experiments were carried out using a SFE unit (Thar Technologies, Model SFE100 System), as illustrated in Figure 2. The apparatus contained a stainless steel extraction cell $(100 \mathrm{~mL}$ capacity), flash stainless steel extraction collector $(250 \mathrm{~mL}$ capacity), cooler, $\mathrm{CO}_{2}$ pump, co-solvent pump and heater. The temperature, pressure and $\mathrm{CO}_{2}$ flow rate of the process were controlled by software connected to the SFE apparatus. Liquid $\mathrm{CO}_{2}(\geq 99.98 \%$, Ultra Pure, Air Product, Lot 1796) from a cylinder was cooled to $-5^{\circ} \mathrm{C}$ and sub- 
sequently pumped at $3 \times 10^{-3} \mathrm{~kg} / \mathrm{min}$.

Before extraction, the system was equilibrated (40 min) at the same conditions as the extraction process. Extractions were carried out at $70^{\circ} \mathrm{C}$ and 200 bar for $1-3 \mathrm{~h}$ (dynamic extraction), based on experimental data from literature [22]. The PCB mixture (Askarel ${ }^{\mathbb{B}}$ ) was collected and quantified by gas chromatography-mass spectrometry (GC/MS).

\subsection{Extract Analysis}

Each extract was mixed with hexane to yield $100 \mathrm{~mL}$ of "pollutant solution". An aliquot $(1 \mathrm{~mL})$ of the "pollutant solution" was placed in vials and analyzed by GC/MS (Varian, Model CG-CP 380 MS-Saturn 2200, VF-5MS) using an automatic injector on a capillary column $(5 \%$ : $95 \%$ diphenyl: dimethyl-polysiloxane, $30 \mathrm{~m} \times 0.25 \mathrm{~mm} \times$ $0.25 \mu \mathrm{m})$. The column temperature program was: $100^{\circ} \mathrm{C}$ for $5 \mathrm{~min}, 4^{\circ} \mathrm{C} / \mathrm{min}$ to $230^{\circ} \mathrm{C}, 230^{\circ} \mathrm{C}$ for $5 \mathrm{~min}, 35^{\circ} \mathrm{C} / \mathrm{min}$ to $280^{\circ} \mathrm{C}, 280^{\circ} \mathrm{C}$ for $5 \mathrm{~min}$ and $30^{\circ} \mathrm{C} / \mathrm{min}$ to $300^{\circ} \mathrm{C}$. The carrier gas was ultra-pure helium $(1.0 \mathrm{~mL} / \mathrm{min})$ and the injection was performed at $260^{\circ} \mathrm{C}$ (split 20:1). Identification and quantification of compounds was based on retention time comparisons with standard solutions. Retention times for the four congeners of polychlorinated biphenyls are shown in Table 2.

\subsection{Statistical Analysis}

\subsubsection{Response Surface Methodology}

The response surface methodology was used for statisti-

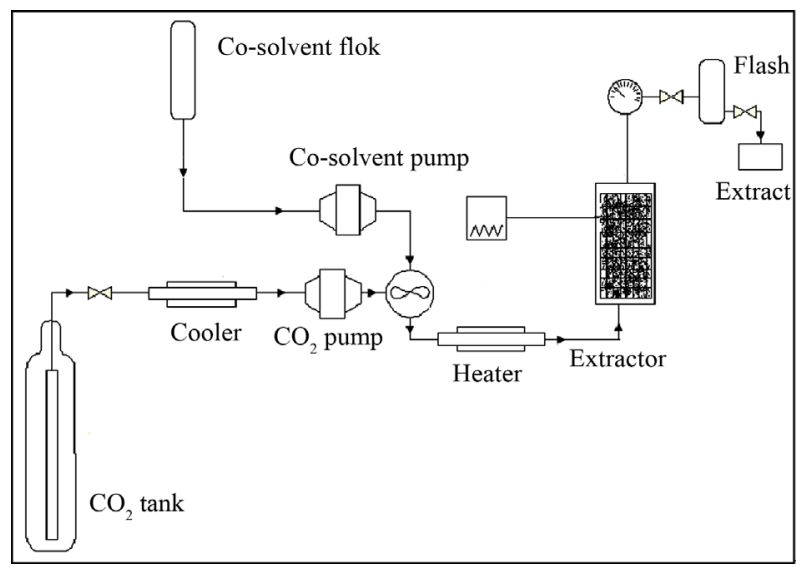

Figure 2. Experimental FE set-up.

Table 2. GC/MS PCB congener retention times.

\begin{tabular}{lc}
\hline PCB congener & Retention time (minutes) \\
\hline Penta-chlorinated & 29.5 \\
Hexa-chlorinated & 33.9 \\
Hepta-chlorinated & 36.9 \\
Octa-chlorinated & 38.9 \\
\hline
\end{tabular}

cal analysis using Statistica Software ${ }^{\circledR}$ (Version 7.0) for regression analyses. The first-order polynomial equation $y=a_{0}+a_{1} x_{1}+a_{2} X_{1} x_{2}$ was used to describe the behavior of the Soxhlet extraction method for plan $\mathrm{H}$ and $\mathrm{E}$. In this polynomial equation, the variables $a_{0}, a_{1}$ and $a_{2}$ are model parameters where $a_{0}$ is the global average of PCB removal. $x_{1}$ (initial soil PCB concentration) and $x_{2}$ (extraction time) represent normalized variables and $y$ is the percentage extraction of reference PCB congeners and total PCBs. The equation was fit to the experimental results at a $95 \%$ confidence level.

\subsubsection{Two-Way Analysis of Variance}

Statistical analysis of the wood extractions was performed using two-way analysis of variance (two-way ANOVA) to evaluate the three extraction methods (supercritical fluid extraction using carbon dioxide and Soxhlet extraction using hexane or ethanol as solvent). The five independent variables were the percentage of total PCB recovery from the soil and/or wood samples and the percentage recoveries of the penta-, hexa-, hepta- and octa-chlorinated congeners. Statistics were carried out using MINITAB Statistical Software (Version 15).

\section{Results and Discussion}

\subsection{PCB Extraction of Contaminated Soils}

\subsubsection{Preliminary Study}

The percentage of PCB removal as a function of extraction time for different initial concentrations of contaminated soil using different solvent extractions are presented in Figure 3. In the first 10 minutes of extraction, a high percentage of PCB removal was obtained for all methods. By the third hour of extraction, the PCB removal slowed for all methods.

The best PCB removal (73\% - 95\%) was observed for

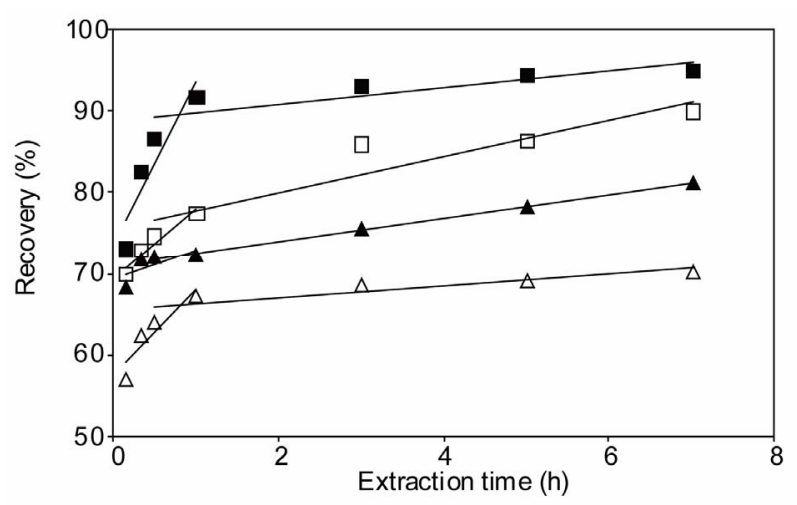

Figure 3. Preliminary Soxhlet extraction tests. ( $\square$ ) $6.000 \mathrm{mg}$ Askarel $^{\circledR} / \mathrm{kg}$ soil, hexane extraction solvent, (घ) $60.000 \mathrm{mg}$ Askare $^{\circledR} / \mathrm{kg}$ soil, hexane extraction solvent, $(\Delta) 6.000 \mathrm{mg}$ Askarel $^{\circledR} / \mathrm{kg}$ soil, ethanol extraction solvent, $(\Delta) 60.000 \mathrm{mg}$ Askarel $^{\circledR} /$ kg soil, ethanol extraction solvent. 
material with a high level of PCB contamination $(60.000$ $\mathrm{mg} \mathrm{Askarel}{ }^{\circledR} / \mathrm{kg}$ soil) at extraction time of $10-420 \mathrm{~min}$ utes using hexane as the extraction solvent.

The initial soil PCB concentration influenced the extraction yield, probably due to the amount of accessible PCB at the surface of the contaminated material. The best results $(95 \%)$ were obtained when hexane was used as the solvent for an extraction time of 420 minutes (7 hours). Unfortunately, hexane is a non-GRAS (Generally Recognized as Safe) solvent, and therefore its toxicity must be considered.

\subsubsection{Statistical Experimental Design and Data Analysis for Conventional Extractions}

Askarel $^{\circledR}$ oil is a mixture of PCBs with some congeners. Therefore, the following five responses were used for each experimental design: percentage removal of total PCBs and percentage removal of penta-, hexa-, hepta- and octachlorinated congeners. In both $\mathrm{H}$ and $\mathrm{E}$ plans, a significant difference between the independent factors (initial soil PCB concentration and extraction time) was observed in the five responses.

\subsubsection{Plan $\mathrm{H}$}

The response surface methodology was used to determine optimized variables for the removal of Askarel ${ }^{\circledR}$ oil by Soxhlet extraction and three-dimensional surface plots were constructed according to Equations (1) to (5).

$$
\begin{gathered}
y_{\text {penta }}=78.14+6.30 x_{1}+6.00 x_{2}-0.50 x_{1} x_{2} \\
y_{\text {hexa }}=77.20+7.20 x_{1}+5.95 x_{2}-1.10 x_{1} x_{2} \\
y_{\text {hepta }}=80.90+5.87 x_{1}+5.72 x_{2}-1.32 x_{1} x_{2} \\
y_{\text {octa }}=80.18+5.50 x_{1}+6.40 x_{2}+0.20 x_{1} x_{2} \\
y_{\text {total }}=82.20+4.42 x_{1}+6.32 x_{2}-0.42 x_{1} x_{2}
\end{gathered}
$$

Figure 4 shows the effect of the initial PCB concentration and extraction time on the removal of penta-chlorinated congener from soil samples. The response surfaces for the other congeners (hexa, hepta, octa-chlorinated and total PCB removal) exhibited behavior similar to that shown in Figure 4.

Analysis of the extraction obtained using this plan showed that both initial concentration and extraction time had significant effects on the extraction of penta-, hexa-, hepta- and octa-chlorinated congeners. In contrast, for total PCB extraction, only extraction time had a significant effect. The interaction of extraction time and initial concentration was not significant for either the congener or total PCB responses. The model showed a satisfactory correlation between the experimental and calculated data, with coefficients of determination $\left(\mathrm{R}^{2}\right)$ of $0.88,0.91,0.91$, 0.89 and 0.87 for removal of penta-, hexa-, hepta- and octa-chlorinated congeners and total PCB, respectively.
The response surfaces also showed that extraction time is an important variable. The results showed that the optimal removal conditions by response surface methodology were initial PCB concentration of $60.000 \mathrm{mg}$ Aska$\mathrm{rel}^{\mathbb{R}} / \mathrm{kg}$ soil and an extraction time of 300 minutes $(5$ hours). At these conditions, 92.0, 91.0, 92.8, 94.1 and 94.3\% removal were obtained for penta-, hexa-, heptaand octa-chlorinated congeners and total $\mathrm{PCBs}$, respectively.

\subsubsection{Plan E}

The response surface methodology was used to determine optimized variables for the removal of Askarel ${ }^{\circledR}$ oil by Soxhlet extraction and three-dimensional surface plots were constructed according to the regression Equations (6) to (10). Equations (6) to (10) represent empirical relationships between the response (y) and the tested variables. The response surfaces obtained show similar behavior to that shown in Figure 4.

$$
\begin{gathered}
y_{\text {penta }}=69.10+6.62 x_{1}+2.87 x_{2}-0.67 x_{1} x_{2} \\
y_{\text {hexa }}=70.78+5.35 x_{1}+1.90 x_{2}-0.60 x_{1} x_{2} \\
y_{\text {hepta }}=68.61+2.75 x_{1}+2.60 x_{2}+0.40 x_{1} x_{2} \\
y_{\text {octa }}=68.62+3.67 x_{1}+5.72 x_{2}+0.63 x_{1} x_{2} \\
y_{\text {total }}=70.69+4.67 x_{1}+3.27 x_{2}-0.02 x_{1} x_{2}
\end{gathered}
$$

In this plan, both initial concentration and extraction time significantly affected the extraction of the penta-, hexaand hepta-chlorinated congeners and total PCBs. For removal of the octa-chlorinated congener, only extraction time had a significant effect.

Statistical analysis indicated that the proposed model

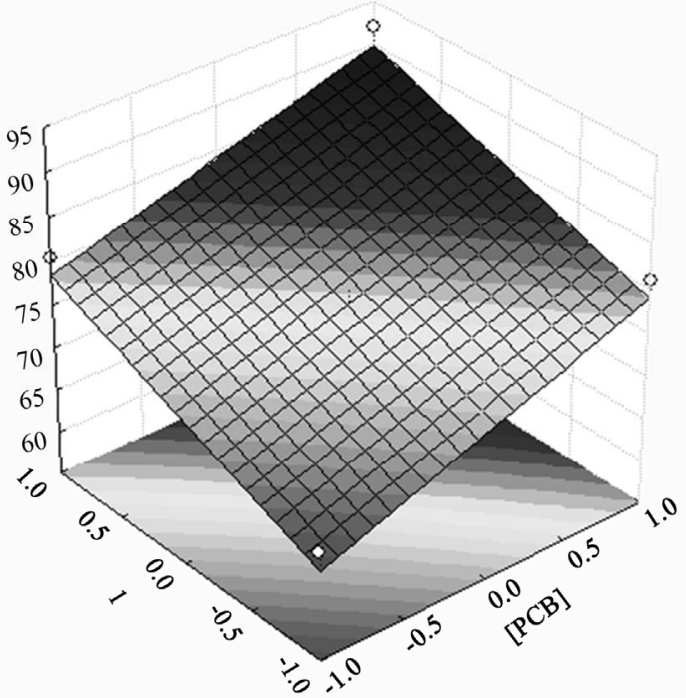

Figure 4. Effect of initial PCB concentration and extraction time on extraction of penta-chlorinated congeners from soil samples. 
was adequate with coefficients of determination $\left(\mathrm{R}^{2}\right)$ of $0.98,0.98,0.92,0.88$ and 0.91 for penta-, hexa-, heptaand octa-chlorinated congeners and total PCBs, respectively. These coefficients indicate that the model for plan E yielded a better model for comparing experimental and calculated data than that obtained for plan $\mathrm{H}$.

According to the response surface methodology results, the optimal conditions for PCB extraction were observed when the extraction time and initial PCB concentration were maximal. Under these conditions, $77.9 \%, 78.0 \%$, $74.0 \%, 77.4 \%$ and $78.3 \%$ extraction were obtained for penta-, hexa-, hepta- and octa-chlorinated congeners and total PCBs, respectively.

\subsubsection{Supercritical Fluid Extractions}

Figure 5 shows the percentage extraction as a function of extraction time for supercritical fluid extractions. The highest extraction by $\mathrm{SC}-\mathrm{CO}_{2}$ was observed after 3 hours of extraction, where the removals varied from $70.5 \% \pm$ $0.9 \%$ for penta-chlorinated congeners to $50 \% \pm 2 \%$ for octa-chlorinated congeners. $57.2 \% \pm 0.2 \%$ of the total PCB congeners were removed under these same conditions.

\subsubsection{Comparison of Extractions Techniques}

Figure 6 shows a comparison of the extractions obtained with Soxhlet extraction using hexane and ethanol, and $\mathrm{SC}-\mathrm{CO}_{2}$ extraction. The extraction using $\mathrm{SC}-\mathrm{CO}_{2}$ varied from $70.5 \% \pm 0.9 \%$ for penta-chlorinated congeners to $50.0 \% \pm 2.0 \%$ for octa-chlorinated congener, with $57.3 \%$ $\pm 0.2 \%$ for total PCB congener extraction after 3 hours of extraction.

For Soxhlet extractions using hexane as the solvent, the PCB extraction varied from $95.9 \% \pm 0.5 \%$ for hexa-chlorinated congeners to $90.7 \% \pm 0.7 \%$ for octa-chlorinated congeners, with $95.0 \% \pm 2.0 \%$ for total PCB congener after 7 hours of extraction. For Soxhlet extractions using ethanol as the solvent, the PCB extraction varied from $78.0 \% \pm 7.0 \%$ for hexa-chlorinated congeners to $84.0 \% \pm 6.0 \%$ for hepta-chlorinated con-

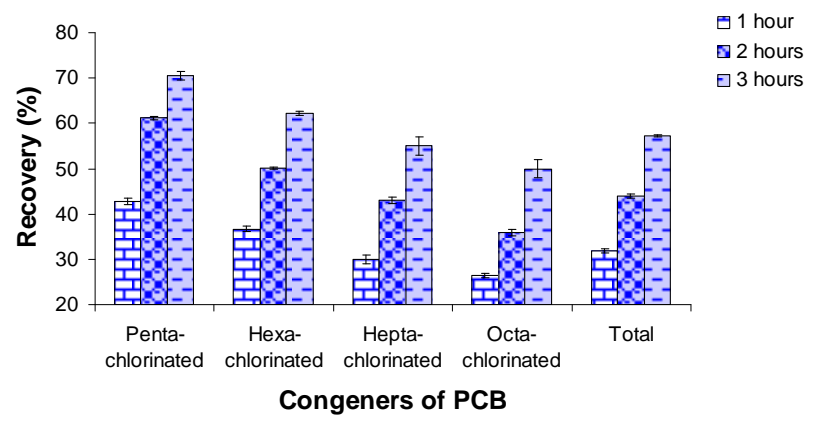

Figure 5. SFE PCB extraction from soil contaminated with $60.000 \mathrm{mg}$ of $\mathrm{PCB}$ mixture/kg soil using $\mathrm{SC}-\mathrm{CO}_{2}\left(70^{\circ} \mathrm{C}, 200\right.$ bar). geners with $81.0 \% \pm 6.0 \%$ for total PCB congeners after 7 hours of extraction. According to these results, there is a difference between these extraction methods as applied to the removal of PCBs from soil (two-way ANOVA, $\mathrm{p}>$ 0.05, Table 3).

\subsection{PCB Extraction from Contaminated Wood}

Figure 7 shows a chromatogram of the extract obtained from Soxhlet extraction ( 7 hours, hexane solvent) of wood contaminated with $60.000 \mathrm{mg}$ of PCB mixture $/ \mathrm{kg}$ wood.

Chromatograms of extracts from Soxhlet extraction using ethanol under similar conditions and SFE extraction using supercritical $\mathrm{CO}_{2}$ were comparable. Figure 8 shows a comparison of extraction recovery for Soxhlet extraction using hexane or ethanol and $\mathrm{SC}-\mathrm{CO}_{2}$.

The PCB extraction using SC- $\mathrm{CO}_{2}$ varied from 91.1\% $\pm 0.9 \%$ for penta-chlorinated congener to $95.0 \% \pm 2.0 \%$ for octa-chlorinated congener, with $95.1 \% \pm 0.5 \%$ for total PCB congeners. For Soxhlet extraction using hexane as the solvent, the PCB extraction varied from $87.0 \%$ $\pm 3.0 \%$ for penta-chlorinated congeners to $94.0 \% \pm 3.0 \%$ for hepta-chlorinated congeners, with $96.3 \% \pm 0.1 \%$ for total PCB congeners. For Soxhlet extraction using ethanol as the solvent, the PCB extraction varied from $89.0 \%$ $\pm 3.0 \%$ for hepta-chlorinated congeners to $94.0 \% \pm 3.0 \%$

Table 3. Two-way ANOVA analysis of the effects of variables (penta-, hexa-, hepta-, octa-chlorinated congeners and total PCBs) and extraction method (Soxhlet extraction with hexane or ethanol, and $\mathrm{SC}-\mathrm{CO}_{2}$ ) for decontamination of soil samples.

\begin{tabular}{cccccc}
\hline $\begin{array}{c}\text { Source of } \\
\text { variation }\end{array}$ & df & $\begin{array}{c}\text { Sum of } \\
\text { squares }\end{array}$ & $\begin{array}{c}\text { Mean } \\
\text { square }\end{array}$ & F & P \\
\hline Variables & 4 & 99.4 & 24.9 & 0.90 & 0.482 \\
Treatment & 2 & 6854.0 & 3427.0 & 123.68 & 0.000 \\
Error & 23 & 637.3 & 27.7 & & \\
Total & 29 & 7590.7 & & & \\
\hline
\end{tabular}

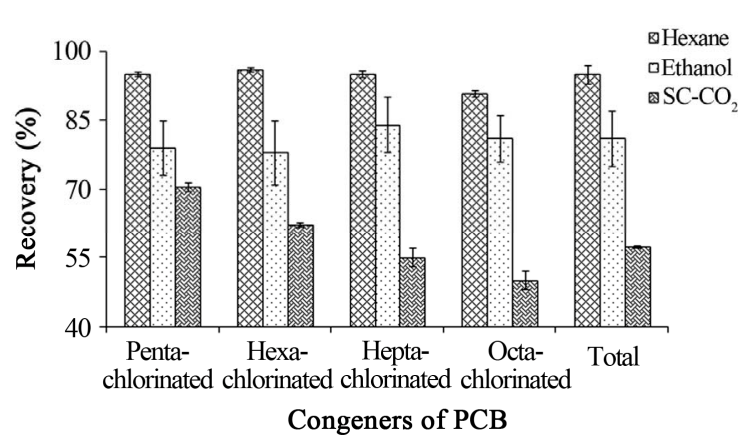

Figure 6. PCB extraction from soil contaminated with 60.000 mg PCB mixture/kg soil. PCB extraction was carried out by the Soxhlet method using hexane or ethanol as the extraction solvent, and by SFE extraction using supercritical $\mathrm{CO}_{2}\left(70^{\circ} \mathrm{C}, 200\right.$ bar $)$. 
for hexa-chlorinated congeners, with $95.0 \% \pm 2.0 \%$ for total PCB congeners. These results indicate that there is no statistically significant difference (two-way ANOVA, $p$ $>0.05$ ) between the three techniques (Table 4).

Although there was no significant difference in PCB extraction for the three techniques, other characteristics can be examined to compare them. Ethanol is a GRAS solvent and therefore Soxhlet extraction with ethanol

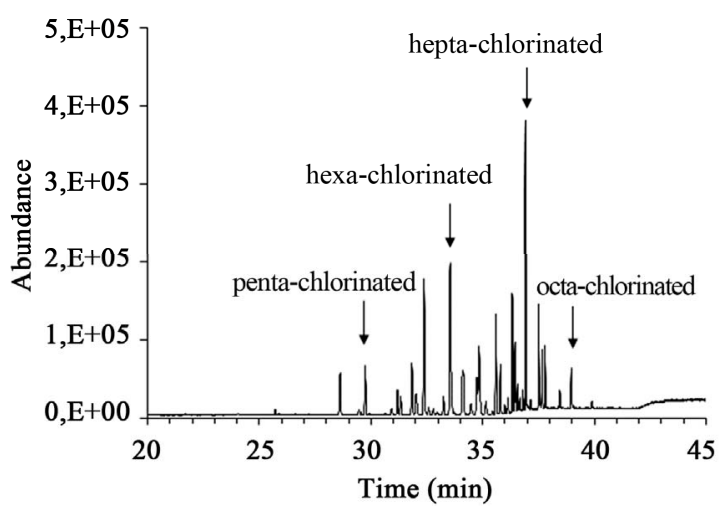

Figure 7. Chromatogram (GC/MS) of the extract obtained from Soxhlet extraction using hexane as solvent, arrows show the congeners of PCBs.

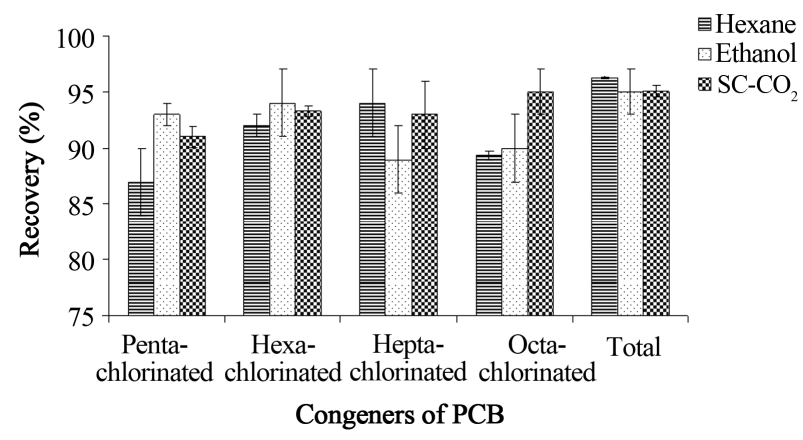

Figure 8. PCB extraction from wood contaminated with $60.000 \mathrm{mg}$ PCB mixture/kg wood. PCB extraction was carried out by the Soxhlet method using hexane or ethanol as the extraction solvent, and by SFE extraction using supercritical $\mathrm{CO}_{2}\left(70^{\circ} \mathrm{C}, 200\right.$ bar $)$.

Table 4. Two-way ANOVA analysis of the effects of variables (penta-, hexa-, hepta-, octa-chlorinated congeners and total PCBs) and extraction method (Soxhlet extraction with hexane or ethanol, and $\mathrm{SC}-\mathrm{CO}_{2}$ ) for decontamination of wood samples.

\begin{tabular}{cccccc}
\hline $\begin{array}{c}\text { Source of } \\
\text { Variation }\end{array}$ & df & $\begin{array}{c}\text { Sum of } \\
\text { squares }\end{array}$ & $\begin{array}{c}\text { Mean } \\
\text { square }\end{array}$ & F & P \\
\hline Variables & 4 & 85.26 & 21.31 & 3,40 & 0.025 \\
Treatment & 2 & 16.07 & 8.03 & 1.28 & 0.296 \\
Error & 23 & 144.04 & 6.26 & & \\
Total & 29 & 245.38 & & & \\
\hline
\end{tabular}

would be better than with hexane because of lower cost and reduced possible toxicity. Furthermore, SFE is a better alternative than Soxhlet extraction as the extraction time to obtain comparable extraction for Soxhlet extractions was 3.5 times longer than SFE, resulting in higher extraction costs. In this study, SFE was evaluated at only one set of conditions $\left(70^{\circ} \mathrm{C}, 200\right.$ bar $)$. Thus, modification of the SFE conditions, such as temperature and pressure, may further improve the PCB extraction from contaminated wood.

\subsection{Comparison of the Contaminated Matrixes}

An important observation is related to application of supercritical extraction to remove PCB from soil and wood. Analyzing the Figures $\mathbf{6}$ and $\mathbf{8}$ it was verified that the removal of PCBs using SFE was more effective in wood (from $91.1 \%$ to $95.0 \%$ ) than in soil (from $70.5 \%$ to $50.0 \%$ ). Some authors trying to explain this kind of occurrence through the characteristics of the solid matrix. The porosity, organic carbon content and composition have direct influence in the extraction [23-24]. Kastanek and Katastanek [12] reported that the high stability, the hydrophobicity and the high affinity of the PCBs to organic compounds affect the extraction power in soil and sediments. Indeed, the extraction of PCBs from soil was more effective when hexane was used. This solvent contains more carbon chain than ethanol. However, this was not observed when wood was the solid matrix. According to Choi and Al-Abed [25], wood is non-porous, has low superficial area, amorphous structure and low adsorption capacity when compared to other materials. These data explain the better efficiency of SFE in the PCB removal from wood.

The difference observed in the extraction of PCBs from soil and wood seems to be due to both effects: the adsorption capacity of the matrixes and the strength of association with the solvent. Bjorklund et al. [26] developed a sequential extraction of PCBs associated with stages of desorbing sites on contaminated sediments and soil using supercritical $\mathrm{CO}_{2}$ from $40^{\circ} \mathrm{C}$ to $150^{\circ} \mathrm{C}$. In their study, it was demonstrated that PCB desorption processes depend on multiple sample characteristics, like sample particle size, water content, organic content, solid matrix. They described that the marine sediment and the industrial soil had the highest fraction of PCBs and were rapidly desorbed from their parent matrixes. On the other hand, the river sediment and Lake Jarnsjon sediment showed much higher proportions of slowly desorbing PCBs. In these last matrixes, the PCBs were not removed until the most rigorous SFE conditions were used. The authors explain that the difference observed in the PCBs desorption was due to strength and the distribution of adsorptive sites in different matrixes. According to this work [26], it is possible to assume that the main cause of the 
observed differences in the removal of PCBs from wood and soil in our study was the characteristics of the solid matrix.

It is also relevant to mention that in processes with supercritical fluid, the molecular weight of compounds to be extracted is an important factor to be considered, because generally the solubility of the compounds supercritical fluids decreases with increasing molecular weight. This behavior was verified in our study in the extraction of PCBs from soil (Figure 6). Therefore, the opposite can also occur. The higher molecular weight of the compounds can promote slower extraction rates. This second occurrence was observed in the extraction of PCBs from wood (Figure 8). In fact, there is no clarity for PCBs which effect is stronger. The results demonstrate that differences in the extraction of various PCB are more dependent on the matrix than on the type of the PCB congener. These same observations were reported by Bjorklund et al. [26] in the extraction of PCBs from different sediments.

\section{Conclusion}

In this study, conventional and supercritical fluid extractions were compared for the extraction of PCBs from contaminated materials in order to determine the most effective and economical, and least toxic method. The extraction performance of the Soxhlet method was dependent on the contaminant concentration and solvent used for extraction. The average PCB extraction using the Soxhlet method with hexane or ethanol was acceptable with greater than $70 \%$ extraction of PCBs. The low cost, easy availability and low toxicity of ethanol make this solvent a better alternative than hexane for use in Soxhlet extractions. Supercritical fluid extraction was also found to be a good alternative to conventional Soxhlet extraction using hexane, mainly when wood is the solid matrix. Supercritical fluid extraction is a good option due to lower solvent use and shorter extraction time. Further studies to optimize SFE conditions are required to promote the application of this technology for the decontamination of PCB-contaminated solid materials. It was also observed that the type of solid matrix has direct influence on removal of contaminants due to their different adsorption capacity.

\section{Acknowledgements}

The authors are grateful to Cepema-USP for laboratory support and Capes (Procad: 213055) for financial support. D.J. Silva also thanks Capes for MS assistance.

\section{REFERENCES}

[1] Greenpeace, Brasil, "Poluentes Orgânicos Persistentes: Po- luição Invisível e Global,” 2011. www.greenpeace.org.br/toxicos/pdf/poluentes.pdf

[2] G. T. Yogui, M. C. O. Santos and R. C. Montore, "Chlorinated Pesticides and Polychlorinated Biphenyls in Marine Tucuxi Dolphins (Sotalia fluviatilis) from the Cananéia Estuary, Southeastern Brazil," Science of the Total Environment, Vol. 312, No. 1-3, 2003, pp. 67-78. doi:10.1016/S0048-9697(03)00198-0

[3] World Health Organization (WHO), "Polychlorinated Biphenyls (PCBs)," 2011.

http://www.euro.who.int/ data/assets/pdf file/0016/123 064/AQG2ndEd_5_10PCBs.PDF

[4] J. C. P. Penteado and J. M. O. Vaz, "O Legado das Bifenilas Policloradas (PCBs)," Quimica Nova, Vol. 24, No. 3, 2001, pp. 390-398. doi:10.1590/S0100-40422001000300016

[5] Agency for Toxic Substancesand DiseaseRegistry (ATS DR), "Toxicological Profile for Polychlorinated Biphenyls (PCBs)," 2000. www.atsdr.cdc.gov/ToxProfiles/tp17.pdf

[6] N. Matsuura, T. Uchyama, H. Tada, Y. Nakamura, N. Kondo, M. Morita and M. Fukushi, "Effects of Dioxins and Polychlorinated Biphenyls (PCBs) on Thyroid Function in Infants born in Japan-The Second Report from Research on Environmental Health," Chemosphere, Vol. 45, No. 8, 2001, pp. 1167-1171. doi:10.1016/S0045-6535(01)00050-9

[7] J. Borja, D. M. Taleon, J. Auresenia and S. Gallardo, "Polychlorinated Biphenyls and Their Biodegradation," Process Biochemistry, Vol. 40, No. 6, 2005, pp. 1999 2013. doi:10.1016/j.procbio.2004.08.006

[8] G. Ross, "The Public Health Implications of Polychlorinated Biphenyls (PCBs) in the Environment," Ecotoxicology and Environmental Safety, Vol. 59, No. 3, 2004, pp. 75-291. doi:10.1016/j.ecoenv.2004.06.003

[9] http://www.tecori.com.br/legislacao/index.html

[10] J. P. Stow, "Chemical Remediation of PCB Contaminated Soils Using Fenton's reagent," Ms Thesis, Royal Military College of Canada, Ontário, 1997.

[11] C. A. B. Tooge, "Uso do Reagente de Fenton Como Oxidante Secundário em Sistemas de Destruição de Resíduos Através de Oxidação téRmica," Ph.D. Thesis, University of São Paulo, São Paulo, 2004.

[12] F. Kastánek and P. Kastánek, “Combined Decontamination Processes for Wastes Containing PCBs," Journal of Hazardous Materials, Vol. 117, No. 2-3, 2005, pp. 185205. doi:10.1016/j.jhazmat.2004.09.026

[13] D. L. Timberlake and J. R. Garbaciak, "Bench-Scale Testing of Selected Remediation Alternatives for Contaminated Sediments," Journal of the Air \& Waste Management Association, Vol. 45, No. 1, 1995, pp. 52-56. doi:10.1080/10473289.1995.10467341

[14] F. W. Chuang, R. A. Larson and M. S. Wessan, "ZeroValent iron Promoted Dechlorination of Polychlorinated Biphenyls," Environmental Science \& Technology, Vol. 29, No. 9, 1995, pp. 2460-2463. doi:10.1021/es00009a044

[15] M. D. Luque de Castro and L. E. García-Ayuso, "Soxhlet 
Extraction of Solid Materials: An Outdated Technique with a Promising Innovative Future," Analytica Chimica Acta, Vol. 369, No. 1-2, 1998, pp. 1-10. doi:10.1016/S0003-2670(98)00233-5

[16] J. R. Bowyer and J. D. Pleil, "Comparison of Supercritical Fluid Extraction and Soxhlet Extraction of Organic Compounds from Carpet Samples," Journal of Chromatography A, Vol. 787, No. 1-2, 1997, pp. 171-179. doi:10.1016/S0021-9673(97)00624-9

[17] M. O. Punın-Crespo and M. A. Lage-Yusty, "Routine Analysis of Hydrocarbons, PCB and PAH in Marine Sediments Using Supercritical $\mathrm{CO}_{2}$ Extraction," Chemosphere, Vol. 38, No. 3, 1999, pp. 587-599. doi:10.1016/S0045-6535(98)00213-6

[18] M. O. Punın Crespo and M. A. Lage Yusty, "Comparison of Supercritical Fluid Extraction and Soxhlet Extraction for the Determination of PCBs in Seaweed Samples," Chemosphere, Vol. 59, No. 10, 2005, pp. 1407-1413. doi:10.1016/j.chemosphere.2004.12.025

[19] T. Nilsson, S. Bowadt and E. BjCorklund, "Development of a Simple Selective SFE Method for the Determination of Desorption Behaviour of PCBs in Two Swedish Sediments," Chemosphere, Vol. 46, No. 3, 2002, pp. 469-476. doi:10.1016/S0045-6535(01)00119-9

[20] N. A. Policarpo, "Tratamento de Solos Contaminados Com Bifenilas Policloradas (PCBs)," Ms Thesis, Universidade de São Paulo, São Paulo, 2008.

[21] D. J. Silva "Tratamento de Materiais Contaminados Com Bifenilas Policloradas (PCBs) via Extração Convencional e Fluído Supercrítico," Ms Thesis, Universidade Federal do Rio Grande do Norte, Natal, 2008.
[22] G. Anitescu and L. L. Tavlarides, "Solubility of Individual Polychlorinated Biphenyl (PCB) Congeners in Supercritical Fluids: $\mathrm{CO}_{2}, \mathrm{CO}_{2} / \mathrm{MeOH}$ and $\mathrm{CO}_{2} / \mathrm{n}-\mathrm{C}_{4} \mathrm{H}_{10}$," The Journal of Supercritical Fluids, Vol. 14, No. 3, 1999, pp. 197-211. doi:10.1016/S0896-8446(98)00109-0

[23] A. C. O. Chagas-Spinelli, "Biorremediação de Solo Argiloso Contaminado por Hidrocarboneto Poliaromáticos Proveniente do Derrame de óleo Diesel," Ms Thesis, Universidade Federal de Pernambuco, Recife, 2007.

[24] A. Kawashima, T. Miyawaki and K. Honda, "Influence of the Characteristics of Soil and fly ash on the Supercritical Carbon Dioxide Extraction of Dioxins," Analytical Sciences: The International Journal of the Japan Society for Analytical Chemistry, Vol. 22, No. 11, 2006, pp. 13931397. doi:10.2116/analsci.22.1393

[25] H. Choi and S. R. Al Abed, "PCB Congener Sorption to Carbonaceous Sediment Components: Macroscopic Comparison, Characterization of Sorption Kinetics and Mechanism," Journal of Hazardous Materials, Vol. 165, No. $1-3,2009$, pp. 860-866. doi:10.1016/j.jhazmat.2008.10.100

[26] E. Bjorklund, S. Bowadt, L. Mathiasson and S. B. Hawthorne, "Determining PCB Sorption/ Desorption Behavior on Sediments Using Selective Supercritical Fluid Extraction. 1. Desorption from Historically Contaminated Samples," Environmental Science \& Technology, Vol. 33, No. 13, 1999, pp. 2193-2203. doi:10.1021/es981071p 